\title{
Health Outcome Inequities and the Health System: A Case Study of Egypt
}

\author{
Hassan H.M. Zaky \\ Research Professor, Social Research Center, American University in Cairo, Egypt \\ Professor of Statistics at the Faculty of Economics and Political Science, Cairo University, Egypt \\ E-mail: hzaky@aucegypt.edu \\ Somaya Ahmed Aly Abdel-Mowla (Corresponding author) \\ Associate Professor of Economics, Faculty of Commerce and Business Administration, \\ Helwan University, Egypt \\ P.O. Box 262, Imbaba, Giza, Post Code 12411, Egypt \\ E-mail: somaya204@yahoo.com
}

Received: August 15, 2011 Accepted: August 29, $2011 \quad$ doi:10.5430/rwe.v2n2p71

Thanks are due to attendees of the 2011 Hawaii International Conference on Social Sciences and to attendees of the 2011 AUC Annual Research Conference on Social Justice for comments and suggestions.

\begin{abstract}
The documentation of health outcome inequities between population groups and/or geographical areas is important to provide evidence for policy actions and for promoting health equity. This paper aims to support the development of a data base on health inequities, consisting of indicators based on aspects of the wider health system, including health inputs, process and outcome indicators. A framework for the health system indicators is used as well as equity measures are applied to highlight inequities in health outcomes and link them to inequities in the health system to answer the question of whether the health system in Egypt is pro-disadvantaged groups. It is found that health outcome inequities pose a challenge for Egypt. Analyzing both determinants and symptoms of health outcome inequities in Egypt demonstrates that the current health system does not help reduce such inequities; on the contrary it leads to increase them.
\end{abstract}

Keywords: Health Economics, Equity, Health System, Health Insurance, Egypt

\section{Introduction}

Over the past three decades, there has been growing interest in equity among national and international health organizations. Equity covers the absence of systematic and potentially remediable differences in one or more aspect of health across subgroups of population defined socially, economically, demographically, or geographically (Macinko \& Starfield, 2002).

Equity and equality are both used in the health equity literature. Some may refer to the two terms as synonymous. However, they are not. A review of the health equity literature (Asada, 2005; Braveman, 2004; Oliver, Healey, \& Le Grand, 2002; Pan America Health Organization-World Health Organization, 1999; Whitehead, 1992) shows that health sciences researchers have increasingly distinguished health inequity from health inequality. Equality is sameness while equity is fairness. In general, equity may be as "justice" and inequity as "injustice”. The issue is not equality of distributions but rather fairness of distributions.

The concept of health equity focuses attention on the distribution of resources and other processes that drive a particular kind of health inequality - that is, a systematic inequality in health between more and less advantaged social groups, in other words, a health inequality that is unjust or unfair. Not all health disparities are unfair. For example, female newborns tend to have lower birth weights on average than male newborns; men have prostate problems, while women do not. It would be difficult, however, to argue that any of these health inequalities is unfair. However, differences in 
nutritional status or immunization levels between girls and boys, or racial differences in the likelihood of receiving appropriate treatment for a heart attack, would be causes for grave concern from an equity perspective. The most common way to depart from strict equality in health outcome is to look at health determinants. We can define health inequalities caused by certain determinants as inequitable.

The objective of this paper is to use a simple framework for the health system in an attempt to show that inequities in the health outcome can be linked to inequities in the health system components. To do so, the components of the health system framework are identified, followed by a brief introduction of the equity measures used in the paper. Examples of outcome indicators are then calculated by region in Egypt and linked to the associated indicators of the other components of the health system in an attempt to raise the question about the role of the health system in Egypt in producing health inequities. The paper tries to answer the question of whether the health system in Egypt is pro-disadvantaged groups or not by investigating the role of the health system in creating or reducing inequities in the outcome and impact indicators.

\section{Methodology and Data}

\subsection{Identifying Health System Components}

The suggested framework for the health system starts with health system inputs passing by the process of delivering health services, the output of the system and ending by the appraisal of the outcome and impact of the system on population health.

The system inputs are dealt with in terms of human resources, financial resources and health facilities. These three subcomponents are assessed by a number of indicators. Another set of indicators is developed to monitor processes operating within the health system. In this framework, health system outputs are classified in terms of the information and skills acquired by the health personals and the public. Two other sets measure the outcomes and impacts of health systems. The outcome indicators assess awareness, behavioral and health practice changes, while the impact ones are evaluated in terms of morbidity, mortality, disability, and health.

\subsection{Health Gap Measures}

This paper relies on simple equity measures, mainly absolute and relative gap measures. These equity measures depend on comparing each group with a reference group which may be the best performance group, the worst performance group, the median group or the total population (UK Department of Health, 2008; Braveman, 2003).

The absolute gap is measured by the difference in the values of the relevant health indicators between the two groups compared; a certain group and the reference group. The lower the value of the gap, the lower the inequity is. There is no inequity if the difference equals zero (UK Department of Health, 2008; Gwatkin et. al., 2007; Gakidou, Murray, \& Frenk, 2000; Turrell \& Mathers, 2001; Macinko \& Starfield, 2002).

The gap can also be measured in relative terms, using the indicator ratio, which is the ratio of the indicator of one group to the indicator of the reference group. Ratios closer to one indicate lower inequity. There is no inequity if the indicator ratio equals one (UK Department of Health, 2008; Gwatkin et. al., 2007; Braveman, 2003).

A large indicator difference can occur with a small indicator ratio, if the reference group indicator value is large. Similarly, a small indicator difference can occur with a large indicator ratio, if the reference group indicator value is small. In this paper, two reference groups are used: 1) the best performance "the most advantaged" group, 2) the total population "the national average for an indicator" so as to identify groups performing worse than average.

\subsection{Data}

The empirical analysis depends on the published results of three main nationally representative household surveys. The first two surveys are the most recent Egypt Demographic and Health Surveys; DHS 2005 and 2008 (El Zanaty \& Way, 2006, 2009). The other survey is the Egypt Household Health Service Utilization and Expenditure Survey (EHHSUES) (El Zanaty, 2002). In addition, data from official sources are used.

\section{Inequities in Outcome and Impact Indicators}

Two outcome indicators and one impact indicator are studied here; namely the nutritional status of children under five, iron supplementation, and the infant mortality rate.

\subsection{Nutritional Status}

Children severe stunting (height for age) is the percentage of children $(<5)$ with a height for age Z-score of below -3 standard deviations of the median reference standard for their age. The source of data is the published results of the Demographic and Health Survey; DHS 2005, 2008 (El Zanaty \& Way, 2006, 2009). 
<Table 1 about here>

As shown in Table 1, child severe stunting was highest among children in Upper Egypt governorates in 2005. Children in Lower Egypt governorates were the most advantaged group. Comparing severe stunting inequities in 2005 and 2008, it is very obvious that there has been a considerable increase in these inequities. In 2008, children in Lower Egypt governorates became the most disadvantaged group while those in Upper Egypt governorates became the most advantaged one in spite of the fact that in both groups malnutrition tended to increase considerably.

Severe stunting (weight for age) is the percentage of children $(<5)$ with a weight for age Z-score of below-3 standard deviations of the median reference standard for their age.

\section{$<$ Table 2 about here>}

According to DHS data (El Zanaty \& Way, 2006, 2009), children severe stunting (weight for age) tended to increase in all governorates except for urban governorates. The most advantaged group was frontier governorates while urban governorates were the most disadvantaged group. Children severe stunting in urban governorates was 1.08 higher than the national average and almost double the percentage in frontier governorates (see Table 2).

\subsection{Iron Supplementation}

Iron supplementation measures the percentage of women with one or more births in the five years before the survey who had taken iron tablets during the most recent pregnancy; "Iron supplementation during pregnancy is recommended to prevent iron deficiency anemia, which is a common problem among pregnant women” (El Zanaty \& Way, 2009, p. 129). DHS data were used to compare iron supplementation across governorates and socioeconomic groups as shown in Table 3.

<Table 3 about here>

The most advantaged group was urban governorates while the most disadvantaged governorates were Upper Egypt governorates in 2005 and the Lower Egypt governorates in 2008 (see Figure 1).

$<$ Figure 1 about here >

Comparing urban and rural areas in 2008 as shown in Table 3, it was found that the percentage of women with one or more births in the five years before the survey who had taken iron tablets during the most recent pregnancy was lower in rural areas than the national average. In contrast, it was higher in urban areas than the national average except for urban Lower Egypt. The rural-urban gap was wider in Upper Egypt governorates than in Lower Egypt governorates. The most disadvantaged area in Egypt was rural Lower Egypt followed by urban Lower Egypt.

Comparing Iron supplementation by other socioeconomic characteristics (see Table 4); it is found that more educated women are more likely to take iron tablets during pregnancy. The percentage of women who had taken iron tablets during their most recent pregnancy was lower among women with less than secondary education than the national average. Wealthier women are more likely to take iron tablets during pregnancy. This is expected as they are usually more educated and more able to afford antenatal care. The percentage in the lowest three quintiles was less than the national average.

<Table 4 about here>

\subsection{Infant Mortality Rate}

One of the main impact indicators of the health system is infant mortality rate per 1000 live births. It measures the probability of a child born in a specific year or period dying before reaching the age of one, if subject to age-specific mortality rates of that period. It is calculated as follows: (total number of infant deaths / total number of live births for specific period) * 1000. Egypt DHS data for 2005 and 2008 were used to evaluate inequities in infant mortality rate.

$<$ Figure 2 about here $>$

$<$ Table 5 about here $>$

The most advantaged area in 2005 was urban governorates. However, in 2008, the most advantaged areas were Lower Egypt governorates followed by frontier governorates. Comparing 2005 and 2008, it was found that the most disadvantaged area in the two years was Upper Egypt governorates (see Table 5). The infant mortality rate in Upper Egypt governorates was higher than the national average in both 2005 and 2008. There was an obvious increase in the infant mortality rate in urban governorates between 2005 and 2008 (see Figure 2). In 2008, infant mortality rate in urban governorates was slightly higher than the national average.

$<$ Figure 3 about here $>$ 
Comparing urban and rural areas (see Figure 3); it was found that infants in urban areas were less likely to die before reaching the age of one than those in rural areas. In all governorates, infant mortality rates were lower in urban areas. Rural-urban gaps have narrowed between 2005 and 2008 as shown in Table 5, except for Lower Egypt governorates.

Evaluating inequities by socioeconomic characteristics (see Table 6); it was found that the higher the mother's education level, the less probability was for the child to die before reaching the age of one. Infant mortality rates were higher than the national average for all mothers with less than secondary education. Wealthier families provide better nutrition and health care for their children. Children in the lowest two quintiles had infant mortality rates higher than the national average.

$<$ Table 6 about here>

Analyzing symptoms of health inequities; inequities in the outputs and impact of the health system, we may conclude that:

By residence; the most disadvantaged groups are those living in rural areas, especially in rural Upper Egypt. Those living in rural areas are obviously more disadvantaged than those in urban areas.

By socioeconomic characteristics; those in the lowest income quintiles and the less educated (with less than secondary education) are the most disadvantaged groups. Those groups depend on the public provision of health services as they are less able to afford private healthcare.

\section{Inequities in Health System Inputs}

Inputs are divided into four groups. The first three groups include health system inputs (human resources, facilities, and financing). The fourth group includes other inputs that affect population health and determine the impact of the health system on population health; i.e. housing environment. The last group plays a very important role in shaping health inequities especially in the long run. Inequities in health outcomes between different areas in Egypt are determined not only by inequities in health resources but also by socioeconomic circumstances; including housing environment conditions. It could also be argued that long term widening inequities are linked to these socioeconomic determinants of health more than to inequities in health system inputs.

\subsection{Human Resources}

The indicator selected here for analysis is doctors per 10000 population. This indicator was calculated as follows: \{total doctors divided by population size $\} * 10000$. Inequities are measured by comparing the four groups of governorates against both the most advantaged governorates and the national average as shown in Table 7 .

\section{$<$ Table 7 about here $>$}

Comparing doctors per 10000 population across governorates reveals that the most disadvantaged area in Egypt is Upper Egypt governorates followed by Lower Egypt governorates. The total number of doctors who provide health services for each 10000 population in Upper Egypt governorates is 30\% lower than in urban governorates and $20 \%$ lower than the national average.

It is worth mentioning that total number of doctors per 10000 population is high in frontier governorates due to low population density rather than abundance of human resources.

There are no significant incentives for doctors to work in Upper Egypt governorates. It is much better for them to work in urban governorates for different reasons including:

a) The ability to earn high incomes is higher in urban governorates. Average per capita income is higher in urban governorates than in Upper Egypt. Percentage of population living in poverty in Upper Egypt is almost six times higher than the percentage in urban governorates; 32.5\% vis-à-vis 5.7\% (Institute of National Planning \& United Nations Development Program, 2008). The difference is more pronounced between urban governorates and rural Upper Egypt, where $68.1 \%$ of population in Upper Egypt lives.

b) In urban governorates, it is much easier for doctors to study in highly qualified educational institutes as these institutes are located mainly in urban areas; $37.5 \%$ of university hospitals are located in urban governorates (Central Agency for Public Mobilization and Statistics, 2009).

c) Young doctors have more opportunities to work in private clinics owned by more experienced doctors who usually work in urban governorates; $44 \%$ of private health units in 2010 were located in urban governorates, while $30 \%$, 24\%, and 2\% were located in Lower Egypt, Upper Egypt and Frontier governorates (calculated using data from Central Agency for Public Mobilization and Statistics, 2011). 


\subsection{Facilities}

The indicator used here for analysis is the total number of beds in health units per 10000 population (see Table 7). The most disadvantaged areas in Egypt are Upper Egypt governorates followed by Lower Egypt governorates. For every 10 000 population living in Upper Egypt governorates, the number of beds in health units is only $39 \%$ of the number of beds available to those living in urban governorates and $70 \%$ of the average number of beds available to Egypt population as a whole.

It is worth mentioning that inequity in the distribution of facilities between urban and rural areas are wide. According to data of the Egypt Human Development Report 2008, the total number of health units available to those living in rural areas is only $20 \%$ of the number of health units available to those in urban areas. This is true for Lower and Upper Egypt governorates (Institute of National Planning \& United Nations Development Program, 2008). Rural areas are the most disadvantaged areas. Accordingly, we may conclude that the distribution of health system resources is not supporting the most disadvantaged areas.

\subsection{Financing}

Health insurance as a financing mechanism plays an important role in reducing health inequities especially in developing countries, through three main mechanisms:

\subsubsection{Increasing Access to Health Services}

Four main factors affect access to medicines. One of these factors set by the World Health Organization is sustainable financing. Sustainable financing in turn is "based on all viable financing mechanisms" (Diaz-Bonilla, Babinard, \& Pinstrup-Andersen, 2001, p.39). Viable financing mechanisms include social health insurance.

\subsubsection{Reducing Financial Barriers to Getting Needed Health Services}

Cost of health services is one of the most deterrent barriers to health care access, especially high-quality health care. This barrier is much more severe for the poor. The availability of health insurance coverage significantly helps overcoming this barrier (Castano et al., 2002). In addition, it reduces the effect of cost on the demand of health services and increases the effect of the quality of health care.

\subsubsection{Reducing Negative Financial Effects of Emergencies}

In the case of sudden emergencies, families without health insurance coverage may lose all their savings.

Thus, health insurance coverage is essential to reducing health inequities and income inequality (Diaz-Bonilla et. al., 2001; Deaton, 2001).

The indicator selected here is health insurance coverage (see Table 8). It is the percentage of individuals covered by the health insurance.

$<$ Table 8 about here>

Upper Egypt governorates are the most disadvantaged governorates followed by Lower Egypt governorates. However, gaps in health insurance coverage are much narrower than gaps in the previous two indicators; human resources and facilities. This is due to the comprehensive school health insurance program adopted in Egypt since the nineties. Table 9 shows the distribution of households that have at least one member covered by health insurance by type of insurance.

$<$ Table 9 about here $>$

Data on distribution of health insurance coverage by type of health insurance is available from the EHHSUES (El Zanaty, 2002). The majority of those households in Upper Egypt have at least one member covered by school insurance. Households that are covered by employee health insurance schemes are only $9 \%$ of households that have at least one member covered by health insurance in Upper Egypt compared with 21.4\% in urban governorates.

Analyzing inequities in the distribution of health insurance coverage between different households by the educational level of the head of the household and the wealth index, we may conclude that households headed by less educated individuals are more likely to be deprived of health insurance coverage (see Figure 4a). Poor households who are in most need of health insurance coverage are less likely to have even one member covered by health insurance (see Figure $4 \mathrm{~b})$.

$<$ Figures 4 a, b about here > 


\section{Housing Environment}

Housing conditions have significant effects on individual health status. These effects have been investigated in many studies (O'Neil, 2000; The Australian Housing and Urban Research Institute - ANU Research Center, 2002; Bonnefoy, Braubach, Krapavickaite, Ormandy, \& Zurlyte, 2003; Lemstra et al., 2006). These studies have demonstrated that there are direct causal relationship between housing conditions and individual health status. We here evaluate inequities in housing conditions, as an important determinant of health status (see Table 10). The source of data is the Egypt Human Development Report 2010 (Institute of National Planning \& United Nations Development Program, 2010).

$<$ Table 10 about here $>$

\subsection{Availability of Drinking Water}

The most advantaged group is urban governorates, while the most disadvantaged governorates are frontier and Upper Egypt governorates. Those living in rural Upper Egypt are the most disadvantaged group.

\subsection{Sanitation Facility}

Access to sanitation is obviously much lower than access to piped water. Approximately half of households (56.5\%) have access to sanitation. In addition, inequities in access to sanitation are so much wider than inequities in access to piped water. Only less than one seventh of households in rural Upper Egypt (13.5\%) have access to sanitation. Less than half the population in Upper Egypt and frontier governorates has access to sanitation, while the vast majority of households in urban governorates (96.8\%) have access to sanitation.

The most deprived governorates are Upper Egypt governorates, where almost one-third of households have access to sanitation. Percentage of households who have access to sanitation in urban governorates is almost threefold the percentage in Upper governorates and more than seven times higher than the percentage in rural Upper Egypt.

In addition, while gaps between urban and rural areas in access to piped water are relatively narrow, gaps in access to sanitation between urban and rural areas are huge. Rural Upper Egypt is the most deprived area; the vast majority of households have no access to sanitation.

\section{Inequities in Process Indicators}

To reduce health inequities between different regions in Egypt, it is not enough to redistribute health system resources. Providing good quality services to all areas especially disadvantaged areas is needed to reduce health outcome inequities. Indicators of the process of delivering health services are divided into two groups:

\subsection{Service Provision and Usage}

Taking the percentage of deliveries attained by medically trained persons as an indicator for service provision, it is found that the most advantaged governorates are urban governorates while the most disadvantaged governorates are Upper Egypt governorates as shown in Table 11. However, comparing gaps in 2005 and 2008, we may conclude that gaps have narrowed.

$<$ Table 11 about here>

The gap is wide between urban and rural areas. The rural-urban gap is widest in Upper Egypt. Rural Upper Egypt is the most deprived area. In 2008, only 59.2\% of deliveries in rural Upper Egypt were attained by medically trained persons compared with $92.3 \%$ in urban governorates.

Evaluating inequities in service provision and usage by socioeconomic characteristics (see Table 12), it is found that the previously identified most disadvantaged groups are the most deprived groups with respect to service provision and usage.

$<$ Table 12 about here>

The percentage of deliveries attained by medically trained persons is higher than the national average only among those who have at least secondary education. The percentage of deliveries attended by medically trained persons is lower than the national average in the lowest two quintiles; i.e. among the poor who are more likely to suffer pregnancy and delivery complications.

\subsection{Quality of Service Provided}

The outcome quality indicator measures satisfaction with the quality of service provided. Egypt Household Health Service Utilization and Expenditure Survey (EHHSUES) data were used to estimate the outcome quality indicator for both outpatient and inpatient services. 
In the healthcare sector, the importance of measuring patient satisfaction is well articulated. Patient satisfaction has been studied and measured extensively as a stand alone construct and as a measure of outcome quality (Gill \& White, 2009). Here, outcome quality is estimated as the percentage of service users who are satisfied with quality of services they receive.

$\mathrm{OQ}_{\mathrm{I}}=\mathrm{SU}_{\mathrm{I}} \div \mathrm{U}_{\mathrm{I}}$

(1)

$\mathrm{OQ}_{\mathrm{O}}=\mathrm{SU}_{\mathrm{O}} \div \mathrm{U}_{\mathrm{O}}$

(2)

Where: OQ refers to outcome quality measured by users' satisfaction, OQ $Q_{I}$ refers to outcome quality of inpatient services, OQo refers to outcome quality of outpatient services, $\mathrm{SU}_{\mathrm{I}}$ refers to users satisfied with the quality of inpatient services, $S U_{O}$ refers to users satisfied with the quality of outpatient services, $U_{I}$ and $U_{O}$ refer to users of inpatient and outpatient services respectively.

It is worth mentioning that there is no data available on outcome quality in different governorates. However, it is well known that the poor and the most disadvantaged regions and groups depend mainly on public provision of health services, especially Ministry of Health and Population (MOHP) services. This is more obvious in the case of inpatient services (see Figures 5 a, b).

$<$ Figures 5 a, b about here $>$

The most deprived areas; Upper Egypt, rural areas, remote areas; specifically frontier governorates and the poorest three quintiles depend more than other groups on MOHP services, especially in the case of inpatient services that cost much more than outpatient services.

$<$ Table 13 about here $>$

Comparing outcome quality of both outpatient and inpatient services by health service provider (see Table 13), it is found that outcome quality of both outpatient and inpatient services provided by the two major public providers; MOHP and HIO (Health Insurance Organization) is lowest. In contrast, outcome quality of both outpatient and inpatient private services is highest. Due to high costs, most deprived groups can not afford private health services, especially when they need to be hospitalized. According to EHHSUES data, 11.1\% and 14\% of MOHP inpatient services users would not have used these services if they had a choice in the case of minor and major surgery respectively, $72.6 \%$ and $67.6 \%$ of them would have chosen to use private services.

\section{Conclusions}

This paper aims at analyzing health outcome inequities in Egypt and examining the link between these inequities and the healthcare system inequities, trying to answer a specific question: "Is the health system in Egypt pro-disadvantaged groups?"

The paper uses a framework for the health system that starts with health system inputs passing by the process of delivering health services, the output of the system and ends up by the appraisal of the outcome and impact of the system on the population health. To measure inequity, absolute and relative health gap measures are estimated. Data from multiple surveys and official sources are used.

It is found that health outcome inequities pose a challenge for Egypt. Analyzing both determinants and symptoms of health inequities in Egypt demonstrates that Upper Egypt is the most disadvantaged area while urban governorates are the most advantaged governorates. The current health system does not help reduce such inequities; on the contrary it leads to increase them.

To reduce health inequities, there is a need to adopt a comprehensive strategy so as to stop health gaps widening further and reduce health inequities. Programs addressing symptoms of health inequities will never be successful unless the causes of these inequities are addressed. Thus, tackling the wider determinants of health inequity is a vital contributor to reducing health inequities. These determinants include factors related to the health system (inputs, process of delivering health services) in addition to socioeconomic conditions. These socioeconomic determinants need to be addressed so as to reverse the long term trend of widening health inequities. This requires a range of programs that address different problems (low educational levels, poor housing conditions, poverty ...etc.). Reducing health inequities requires using both health and social policies.

It is advised to distribute health investments and investments in other social sectors unequally among different governorates in favor of the most deprived areas. Improving overall health status in Egypt is necessary. However, it is 
not enough to close health gaps; these gaps may remain the same or may be wider if health status in advantaged areas improves at a faster rate.

In addition, tracking health inequities over time is essential to evaluate future trends in health inequities. This should be done through a health equity observatory.

\section{References}

Asada, Y. (2005). A framework for measuring health inequity. Journal of Epidemiology and Community Health, 59, 700-705. http://dx.doi.org/10.1136/jech.2004.031054

Bonnefoy, X., Braubach, M., Krapavickaite, D., Ormandy, D., \& Zurlyte, I. (2003). Housing conditions and self-reported health status: A study in panel block buildings in three cities of Eastern Europe. Journal of Housing and the Built Environment, 18 (4), 329-352. http://dx.doi.org/10.1023/B:JOHO.0000005757.37088.a9

Braveman, P. (2003). Monitoring equity in health and healthcare: A conceptual framework. Journal of Health, Population and Nutrition, 21(3), 181-192.

Braveman, P. (2004). Defining equity in health. Health Policy and Development, 2(3), 180-185.

Castano, R. A., Arbelaez, J. J., Giedion, U. B., \& Morales, L. G. (2002). Equitable financing, out-of-pocket payments and the role of health care reform in Colombia. Health Policy and Planning, 17(Suppl1), 5-11. http://dx.doi.org/10.1093/heapol/17.suppl_1.5

Central Agency for Public Mobilization and Statistics. (2009). Facilities and human resources in the public health sector 2008. Cairo: Author.

Central Agency for Public Mobilization and Statistics. (2011). Egypt in figures 2010. Cairo: Author.

Deaton, A. (2001). Health, inequality and economic development (NBER Working Paper 8318). Cambridge: National Bureau of Economic Research.

Diaz-Bonilla, E., Babinard, J., \& Pinstrup-Andersen, P. (2001). Globalization and health: A survey of opportunities and risks of the poor in developing countries (CMH Working Paper 11). Geneva: WHO, Commission on Macroeconomics and Health.

El Zanaty, F. (2002). Egypt household health service utilization and expenditure survey 2002. Cairo: Ministry of Health, Health Sector Reform Program and El-Zanaty and Associates.

El Zanaty, F., \& Way, A. (2006). Egypt Demographic and Health Survey 2005. Cairo: Ministry of Health, El-Zanaty and Associates, and Macro International.

El Zanaty, F., \& Way, A. (2009). Egypt Demographic and Health Survey 2008. Cairo: Ministry of Health, El-Zanaty and Associates, and ORC Macro.

Gakidou, E.E., Murray, C.J.L., \& Frenk, J. (2000). Defining and measuring health inequality: An approach based on the distribution of health expectancy. Bulletin of the World Health Organization, 78(1), 42-54.

Gill, L., \& White, L. (2009). Critical review of patient satisfaction. Leadership in Health Services, 22(1), 8-19. http://dx.doi.org/10.1108/17511870910927994

Gwatkin, D. R., Rutstein, S., Johnson, K., Suilman, E., Wagstaff, A., \& Amouzou, A. (2007). Socio-economic differences in health, nutrition and population. Washington, DC: World Bank.

Institute of National Planning and United Nations Development Program. (2008). Egypt human development report 2008. Cairo: Authors.

Institute of National Planning and United Nations Development Program. (2010). Egypt human development report 2010. Cairo: Authors.

Lemstra, M., Neudorf, C., Gibson, T., Rea, L., Torr, D., Waren, L., et al. (2006). A systematic literature review of housing health assessment instruments. Environmental Health Review, 10-12.

Macinko, J. A., \& Starfield, B. (2002). Annotated bibliography on equity in health, 1980-2001. International Journal for Equity in Health, 1, 1-.20.

Oliver, A., Healey, A., \& Le Grand, J. (2002). Addressing health inequalities. The Lancet, 360 (9332), 565-567. http://dx.doi.org/10.1016/S0140-6736(02)09713-1 
O'Neil, John (2000). Housing conditions and health: A review of literature. A Report Prepared for the Grand Council of the Crees (Eeyou Istchee). [Online] Available: http://www.creehealth.org/ojs/index.php/cree/article/viewFile/52/48 (June 18, 2009)

Pan America Health Organization, Division of Health and Human Development. (1999). Principles and basic concepts of equity and health. Washington, DC: Author.

The Australian Housing and Urban Research Institute. (2002). Do housing conditions make a difference to our health? AHURI Research \& Policy Bulletin,6, 1-4.

The Egyptian Cabinet Information and Decision Support Center. (2009). Egypt's description by information 2009: Years of development. Cairo: Author.

Turrell, G., \& Mathers, C. (2001). Socioeconomic inequalities in all-cause and specific-cause mortality in Australia: 1985-1987 and 1995-1997. International Journal of Epidemiology, 30(2), $231-239$. http://dx.doi.org/10.1093/ije/30.2.231

UK Department of Health. (2008). Tackling health inequalities: 2007 status report on the Program for action. London: Author.

Whitehead, M. (1992). The concepts and principles of equity and health. International Journal of Health Services, 22(3), 429-445. http://dx.doi.org/10.2190/986L-LHQ6-2VTE-YRRN

Table 1. Children severe stunting (height for age): Absolute and relative gaps

\begin{tabular}{|c|c|c|c|c|c|c|c|c|}
\hline \multirow[t]{3}{*}{ Governorates } & \multicolumn{4}{|c|}{ Absolute gaps } & \multicolumn{4}{|c|}{ Relative gaps } \\
\hline & \multicolumn{2}{|c|}{$1 *$} & \multicolumn{2}{|c|}{$2 * *$} & \multicolumn{2}{|c|}{$1 *$} & \multicolumn{2}{|c|}{$2 * *$} \\
\hline & 2005 & 2008 & 2005 & 2008 & 2005 & 2008 & 2005 & 2008 \\
\hline Urban & 0.7 & 2.5 & -0.3 & -2.0 & 1.13 & 1.26 & 0.95 & 0.86 \\
\hline Lower Egypt & 0.0 & 9.3 & -1.0 & 4.8 & 1.00 & 1.98 & 0.84 & 1.34 \\
\hline Upper Egypt & 1.9 & 0.0 & 0.9 & -4.5 & 1.35 & 1.00 & 1.14 & 0.68 \\
\hline Frontier & 0.4 & 5.5 & -0.6 & 1.0 & 1.07 & 1.58 & 0.91 & 1.07 \\
\hline Egypt & 1.0 & 4.5 & 0.0 & 0.0 & 1.19 & 1.47 & 1.00 & 1.00 \\
\hline
\end{tabular}

* Reference group is the most advantaged governorates; Lower Egypt governorates in 2005 and Upper Egypt governorates in 2008, ** Reference group is the national average. Source: calculated using DHS data in El Zanaty and Way (2006, 2009).

Table 2. Children severe stunting (weight for age): Absolute and relative gaps

\begin{tabular}{|c|c|c|c|c|c|c|c|c|}
\hline \multirow[t]{3}{*}{ Governorates } & \multicolumn{4}{|c|}{ Absolute gaps } & \multicolumn{4}{|c|}{ Relative gaps } \\
\hline & \multicolumn{2}{|c|}{$1 *$} & \multicolumn{2}{|c|}{$2 * *$} & \multicolumn{2}{|c|}{$1 *$} & \multicolumn{2}{|c|}{$2 * *$} \\
\hline & 2005 & 2008 & 2005 & 2008 & 2005 & 2008 & 2005 & 2008 \\
\hline Urban & 1.4 & 0.7 & 0.8 & 0.1 & 4.50 & 2.00 & 1.80 & 1.08 \\
\hline Lower Egypt & 0.5 & 0.6 & -0.1 & 0.0 & 2.25 & 1.86 & 0.90 & 1.00 \\
\hline Upper Egypt & 0.4 & 0.5 & -0.2 & -0.1 & 2.00 & 1.71 & 0.80 & 0.92 \\
\hline Frontier & 0.0 & 0.0 & -0.6 & -0.6 & 1.00 & 1.00 & 0.40 & 0.54 \\
\hline Egypt & 0.6 & 0.6 & 0.0 & 0.0 & 2.50 & 1.86 & 1.00 & 1.00 \\
\hline
\end{tabular}

* Reference group is the most advantaged governorates "Frontier governorates", ** Reference group is the national average. Source: calculated using DHS data in El Zanaty and Way (2006, 2009). 
Table 3. Iron supplementation: Absolute and relative gaps

\begin{tabular}{|c|c|c|c|c|c|c|c|c|c|c|}
\hline \multirow{2}{*}{ Governorates } & \multicolumn{4}{|c|}{ Absolute gaps } & \multicolumn{4}{c|}{ Relative gaps } & \multicolumn{2}{c|}{ Rural/Urban } \\
\cline { 2 - 12 } & \multicolumn{2}{|c|}{$1^{*}$} & \multicolumn{2}{c|}{$2^{* *}$} & \multicolumn{2}{c|}{$1^{*}$} & \multicolumn{2}{c|}{$2^{* *}$} & \multicolumn{2}{c}{} \\
\cline { 2 - 12 }$n$ & 2005 & 2008 & 2005 & 2008 & 2005 & 2008 & 2005 & 2008 & 2005 & 2008 \\
\hline Urban & 0.0 & 0.0 & 17.6 & 19.2 & 1.00 & 1.00 & 1.31 & 1.44 & - & - \\
\hline Lower Egypt & -14.4 & -27.5 & 3.2 & -8.3 & 0.81 & 0.56 & 1.06 & 0.81 & 0.88 & 0.99 \\
\hline Upper Egypt & -27.1 & -17.9 & -9.5 & 1.3 & 0.63 & 0.72 & 0.83 & 1.03 & 0.75 & 0.79 \\
\hline Frontier & -13.9 & -20.6 & 3.7 & -1.4 & 0.81 & 0.67 & 1.07 & 0.97 & - & - \\
\hline Egypt & -17.6 & -19.2 & 0.0 & 0.0 & 0.76 & 0.69 & 1.00 & 1.00 & 0.77 & 0.73 \\
\hline
\end{tabular}

* Reference group is the most advantaged governorates "Urban governorates", ** Reference group is the national average. Source: calculated using DHS data in El Zanaty and Way $(2006,2009)$.

Table 4. Iron supplementation by education level and wealth quintile: Absolute and relative gaps- 2008

\begin{tabular}{|c|c|c|c|c|c|c|c|c|c|}
\hline \multirow[t]{2}{*}{ Education } & \multicolumn{2}{|c|}{ Absolute gaps } & \multicolumn{2}{|c|}{ Relative gaps } & \multirow{2}{*}{$\begin{array}{l}\text { Wealth } \\
\text { quintiles }\end{array}$} & \multicolumn{2}{|c|}{ Absolute gaps } & \multicolumn{2}{|c|}{ Relative gaps } \\
\hline & 1* & $2 * *$ & $1^{*}$ & $2 * *$ & & $1 * * *$ & $2 * *$ & $1 * * *$ & $2 * *$ \\
\hline No education & -12.5 & -8.1 & 0.74 & 0.81 & 1 & -24.8 & -8.4 & 0.59 & 0.81 \\
\hline Some primary & -10.5 & -6.1 & 0.78 & 0.86 & 2 & -22.9 & -6.5 & 0.62 & 0.85 \\
\hline $\begin{array}{l}\text { Primary complete/some } \\
\text { secondary }\end{array}$ & -5 & -0.6 & 0.90 & 0.99 & 3 & -22 & -5.6 & 0.63 & 0.87 \\
\hline Secondary complete/higher & 0.0 & 4.4 & 1.00 & 1.1 & 4 & -13.3 & 3.1 & 0.78 & 1.07 \\
\hline & & & & & 5 & 0.0 & 16.4 & 1.00 & 1.38 \\
\hline Egypt & -4.4 & 0.0 & 0.91 & 1.00 & Egypt & -16.4 & 0.0 & 0.73 & 1.00 \\
\hline
\end{tabular}

* Reference group is the most advantaged group "secondary complete/higher", ** Reference group is the national average, *** Reference group is the most advantaged group "the wealthiest quintile (5)". Source: calculated using DHS data in El Zanaty and Way (2006, 2009).

Table 5. Infant mortality gaps by region

\begin{tabular}{|c|c|c|c|c|c|c|c|c|c|c|}
\hline \multirow{2}{*}{ Governorates } & \multicolumn{4}{|c|}{ Absolute gaps } & \multicolumn{4}{c|}{ Relative gaps } & \multicolumn{3}{c|}{ Rural/Urban } \\
\cline { 2 - 11 } & \multicolumn{2}{|c|}{$1^{*}$} & \multicolumn{2}{|c|}{$2^{* *}$} & \multicolumn{2}{c|}{$1^{*}$} & \multicolumn{2}{|c|}{$2^{* *}$} & \multirow{2}{*}{2008} \\
\cline { 2 - 12 }$n$ & 2005 & 2008 & 2005 & 2008 & 2005 & 2008 & 2005 & 2008 & 2005 & - \\
\hline Urban & 0.0 & 8.4 & -9.9 & 1.1 & 1.00 & 1.39 & 0.72 & 1.04 & - & - \\
\hline Lower Egypt & 6.7 & 0.0 & -3.2 & -7.3 & 1.26 & 1.00 & 0.91 & 0.74 & 1.12 & 1.57 \\
\hline Upper Egypt & 25.6 & 15.0 & 15.7 & 7.7 & 1.98 & 1.70 & 1.44 & 1.27 & 1.43 & 1.29 \\
\hline Frontier & 7.3 & 2.8 & -2.6 & -4.5 & 1.28 & 1.13 & 0.93 & 0.84 & - & - \\
\hline Egypt & 9.9 & 7.3 & 0.0 & 0.0 & 1.38 & 1.34 & 1.00 & 1.00 & 1.43 & 1.20 \\
\hline
\end{tabular}

* Reference group is the most advantaged governorates "Urban governorates" for 2005 and "Lower Egypt Governorates" for 2008, ** Reference group is the national average. Source: calculated using DHS data in El Zanaty and Way (2006, 2009). 
Table 6. Infant mortality by education level and wealth quintile: Absolute and relative gaps- 2008

\begin{tabular}{|c|c|c|c|c|c|c|c|c|c|}
\hline \multirow[t]{2}{*}{ Education } & \multicolumn{2}{|c|}{ Absolute gaps } & \multicolumn{2}{|c|}{ Relative gaps } & \multirow{2}{*}{$\begin{array}{l}\text { Wealth } \\
\text { quintiles }\end{array}$} & \multicolumn{2}{|c|}{ Absolute gaps } & \multicolumn{2}{|c|}{ Relative gaps } \\
\hline & $1 *$ & $2 * *$ & $1^{*}$ & $2 * *$ & & $1 * * *$ & $2 * *$ & $1 * * *$ & $2 * *$ \\
\hline No education & 15.4 & 9.0 & 1.69 & 1.31 & 1 & 25.3 & 13.5 & 2.51 & 1.47 \\
\hline Some primary & 7.1 & 0.7 & 1.32 & 1.02 & 2 & 13.7 & 1.9 & 1.82 & 1.07 \\
\hline $\begin{array}{l}\text { Primary complete/some } \\
\text { secondary }\end{array}$ & 7.1 & 0.7 & 1.32 & 1.02 & 3 & 9.4 & -2.4 & 1.56 & 0.92 \\
\hline Secondary complete/higher & 0.0 & -6.4 & 1.00 & 0.78 & 4 & 7.8 & -4.0 & 1.46 & 0.86 \\
\hline & & & & & 5 & 0.0 & -11.8 & 1.00 & 0.59 \\
\hline Egypt & 6.4 & 0.0 & 1.29 & 1.00 & Egypt & 11.8 & 0.0 & 1.70 & 1.00 \\
\hline
\end{tabular}

* Reference group is the most advantaged group "secondary complete/higher", ** Reference group is the national average, *** Reference group is the most advantaged group "the wealthiest quintile (5)". Source: calculated using DHS data in El Zanaty and Way (2006, 2009).

Table 7. Health employment and beds per 10000 population: Absolute and relative gaps

\begin{tabular}{|c|c|c|c|c|c|c|c|c|}
\hline \multirow{2}{*}{ Governorates } & \multicolumn{4}{|c|}{ Absolute gaps } & \multicolumn{4}{c|}{ Relative gaps } \\
\cline { 2 - 10 } & \multicolumn{2}{|c|}{$1^{*}$} & \multicolumn{2}{|c|}{$2^{* *}$} & \multicolumn{2}{c|}{$1^{*}$} & \multicolumn{2}{c|}{$2^{* *}$} \\
\cline { 2 - 9 } & $\mathrm{E}^{* * *}$ & $\mathrm{~B}^{* * *}$ & $\mathrm{E}$ & $\mathrm{B}$ & $\mathrm{E}$ & $\mathrm{B}$ & $\mathrm{E}$ & $\mathrm{B}$ \\
\hline Urban & -2.9 & 0 & 1.2 & 16.1 & 0.74 & 1.0 & 1.2 & 1.8 \\
\hline Lower Egypt & -3.6 & -20 & 0.5 & -3.9 & 0.68 & 0.46 & 1.1 & 0.8 \\
\hline Upper Egypt & -5.4 & -22.4 & -1.3 & -6.3 & 0.51 & 0.39 & 0.8 & 0.7 \\
\hline Frontier & 0 & -9.7 & 4.1 & 6.4 & 1.0 & 0.74 & 1.6 & 1.3 \\
\hline Egypt & -4.1 & -16.1 & 0 & 0 & 0.63 & 0.56 & 1 & 1 \\
\hline
\end{tabular}

* Reference group is the most advantaged governorates, $* *$ Reference group is the national average, *** $\mathrm{E}$ refers to health employment (doctors) per 10000 population 2007, B refers to beds per 10000 population 2007. Source: doctors and beds per 10000 population in addition to absolute and relative gaps are calculated using data from the Egyptian Cabinet Information and Decision Support Center (2009).

Table 8. Health insurance coverage \%: Absolute and relative gaps

\begin{tabular}{|c|c|c|c|c|}
\hline \multirow{2}{*}{ Governorates } & \multicolumn{2}{|c|}{ Absolute gaps } & \multicolumn{2}{c|}{ Relative gaps } \\
\cline { 2 - 5 } & $1^{*}$ & $2^{* *}$ & $1 *$ & $2^{* *}$ \\
\hline Urban & 0.0 & 6.7 & 0.79 & 0.98 \\
\hline Lower Egypt & -7.3 & -0.6 & 0.71 & 0.88 \\
\hline Upper Egypt & -9.9 & -3.2 & 0.81 & 1.01 \\
\hline Frontier & -6.4 & 0.3 & 0.80 & 1.00 \\
\hline Egypt & -6.7 & 0.0 & & 0.00 \\
\hline
\end{tabular}

* Reference group is the most advantaged governorates "Urban governorates", ** Reference group is the national average. Source: calculated using DHS 2008 data in El Zanaty and Way (2009). 
Table 9. Distribution of households who have at least one member covered by health insurance by type of health insurance \%

\begin{tabular}{|c|c|c|c|c|c|}
\hline Governorates & $\begin{array}{c}\text { Employee } \\
\text { insurance }\end{array}$ & $\begin{array}{c}\text { Health insurance } \\
\text { organization }\end{array}$ & $\begin{array}{c}\text { Syndicate } \\
\text { insurance }\end{array}$ & School insurance & Other types \\
\hline Urban & 21.4 & 58.6 & 8.6 & 58.0 & 7.1 \\
\hline Lower Egypt & 13.0 & 63.1 & 1.8 & 68.7 & 4.1 \\
\hline Upper Egypt & 9.0 & 57.6 & 2.8 & 74.9 & 1.9 \\
\hline Frontier & 36.7 & 66.3 & 2.0 & 57.1 & 1.0 \\
\hline Egypt & 13.3 & 60.4 & 3.4 & 69.0 & 3.8 \\
\hline
\end{tabular}

Source: El Zanaty (2002).

Table 10. Households with access to piped water and sanitation \% - 2008

\begin{tabular}{|c|c|c|c|c|c|c|c|c|c|c|}
\hline \multirow{2}{*}{ Governorates } & \multicolumn{4}{|c|}{ Absolute gaps } & \multicolumn{3}{c|}{ Relative gaps } & \multicolumn{3}{c|}{ Rural/Urban } \\
\cline { 2 - 13 } & \multicolumn{2}{|c|}{$1^{*}$} & \multicolumn{2}{|c|}{$2^{* *}$} & \multicolumn{2}{c|}{$1^{*}$} & \multicolumn{2}{|c|}{$2^{* *}$} & \multirow{2}{*}{$\mathrm{S}$} \\
\cline { 2 - 13 } & $\mathrm{P}^{* * *}$ & $\mathrm{~S}^{* * *}$ & $\mathrm{P}$ & $\mathrm{S}$ & $\mathrm{P}$ & $\mathrm{S}$ & $\mathrm{P}$ & $\mathrm{S}$ & $\mathrm{P}$ & - \\
\hline Urban & 0.0 & 0.0 & 1.9 & 40.3 & 1 & 1 & 1.02 & 1.71 & - & - \\
\hline Lower Egypt & -1.3 & -2.2 & 0.6 & 38.1 & 0.99 & 0.98 & 1.01 & 1.67 & 0.98 & 0.56 \\
\hline Upper Egypt & -3.0 & -59.6 & -1.1 & -19.3 & 0.97 & 0.38 & 0.99 & 0.66 & 0.95 & 0.18 \\
\hline Frontier & -11.5 & -54 & -9.6 & -13.7 & 0.88 & 0.44 & 0.90 & 0.76 & - & - \\
\hline Egypt & -1.9 & -40.3 & 0.0 & 0.0 & 0.98 & 0.58 & 1 & 1 & 0.97 & 0.41 \\
\hline
\end{tabular}

* Reference group is the most advantaged governorates "Urban governorates", ** Reference group is the national average, ${ }^{* * *} \mathrm{P}$ refers to access to piped water, $\mathrm{S}$ refers to access to sanitation. Source: calculated using data of EgyptHuman Development Report 2010 (Institute of National Planning \& United Nations Development Program, 2010).

Table 11. Delivery attained by a medically trained person \%

\begin{tabular}{|c|c|c|c|c|c|c|c|c|c|c|}
\hline \multirow{2}{*}{ Governorates } & \multicolumn{4}{|c|}{ Absolute gaps } & \multicolumn{4}{c|}{ Relative gaps } & \multicolumn{3}{c|}{ Rural/Urban } \\
\cline { 2 - 12 } & \multicolumn{2}{|c|}{$1^{*}$} & \multicolumn{2}{|c|}{$2^{* *}$} & \multicolumn{3}{|c|}{$1^{*}$} & \multirow{2}{*}{$2 * 05$} & 2008 \\
\cline { 2 - 12 }$n$ & 2005 & 2008 & 2005 & 2008 & 2005 & 2008 & 2005 & 2008 & 2005 & - \\
\hline Urban & 0.0 & 0.0 & 16.5 & 13.4 & 1.00 & 1.00 & 1.22 & 1.17 & - & - \\
\hline Lower Egypt & -9.1 & -7.0 & 7.4 & 6.4 & 0.9 & 0.92 & 1.10 & 1.08 & 0.84 & 0.91 \\
\hline Upper Egypt & -28.1 & -25.9 & -11.6 & -12.5 & 0.69 & 0.72 & 0.84 & 0.84 & 0.65 & 0.69 \\
\hline Frontier & -18.9 & -13.2 & -2.4 & 0.2 & 0.79 & 0.86 & 0.97 & 1.00 & - & - \\
\hline Egypt & -16.5 & -13.4 & 0.0 & 0.0 & 0.82 & 0.85 & 1.00 & 1.00 & 0.74 & 0.80 \\
\hline
\end{tabular}

* Reference group is the most advantaged governorates "Urban governorates", ** Reference group is the national average. Source: calculated using DHS data in El Zanaty and Way (2006, 2009). 
Table 12. Delivery attained by a medically trained person by education level and wealth quintile 2008

\begin{tabular}{|c|c|c|c|c|c|c|c|c|c|}
\hline \multirow[t]{2}{*}{ Education } & \multicolumn{2}{|c|}{ Absolute gaps } & \multicolumn{2}{|c|}{ Relative gaps } & \multirow{2}{*}{$\begin{array}{l}\text { Wealth } \\
\text { quintiles }\end{array}$} & \multicolumn{2}{|c|}{ Absolute gaps } & \multicolumn{2}{|c|}{ Relative gaps } \\
\hline & $1^{*}$ & $2 * *$ & $1 *$ & $2 * *$ & & $1^{* * *}$ & $2 * *$ & $1^{* * *}$ & $2 * *$ \\
\hline No education & -29.3 & -19.2 & 0.67 & 0.76 & 1 & -41.7 & -23.7 & 0.57 & 0.70 \\
\hline Some primary & -15.9 & -5.8 & 0.82 & 0.93 & 2 & -26.8 & -8.8 & 0.72 & 0.89 \\
\hline $\begin{array}{l}\text { Primary complete/some } \\
\text { secondary }\end{array}$ & -9.7 & 0.4 & 0.89 & 1.01 & 3 & -14.1 & 3.9 & 0.85 & 1.05 \\
\hline Secondary complete/higher & 0.0 & 10.1 & 1.00 & 1.13 & 4 & -6.2 & 11.8 & 0.94 & 1.15 \\
\hline & & & & & 5 & 0.0 & 18 & 1.00 & 1.23 \\
\hline Egypt & -10.1 & 0.0 & 0.89 & 1.00 & Egypt & -18 & 0.0 & 0.81 & 1.00 \\
\hline
\end{tabular}

* Reference group is the most advantaged group "secondary complete/higher", ** Reference group is the national average, *** Reference group is the most advantaged group "the wealthiest quintile (5)". Source: calculated using DHS data in El Zanaty and Way (2009).

Table 13. Outcome quality by health service provider: Outpatient and inpatient services- 2002

\begin{tabular}{|c|c|c|c|c|c|c|c|c|}
\hline \multirow[b]{3}{*}{ Health service provider } & \multicolumn{4}{|c|}{ Absolute gaps } & \multicolumn{4}{|c|}{ Relative gaps } \\
\hline & \multicolumn{2}{|c|}{$1^{*}$} & \multicolumn{2}{|c|}{$2 * *$} & \multicolumn{2}{|c|}{$1^{*}$} & \multicolumn{2}{|c|}{$2 * *$} \\
\hline & $\overline{\mathrm{OQ}_{\mathrm{I}}}$ & $\mathrm{OQ}_{\mathrm{O}}$ & $\mathrm{OQ}_{\mathrm{I}}$ & $\mathrm{OQ}_{\mathrm{O}}$ & $\mathrm{OQ}_{\mathrm{I}}$ & $\mathrm{OQ}_{\mathrm{O}}$ & $\mathrm{OQ}_{\mathrm{I}}$ & $\mathrm{OQ}_{\mathrm{o}}$ \\
\hline $\begin{array}{l}\text { Ministry of Health and } \\
\text { Population (MOHP) }\end{array}$ & -8.8 & -14.5 & -2.4 & -4.4 & 0.91 & 0.85 & 0.97 & 0.95 \\
\hline $\begin{array}{c}\text { Health Insurance } \\
\text { Organization (HIO) }\end{array}$ & -9.3 & -12.9 & -2.9 & -2.8 & 0.90 & 0.87 & 0.97 & 0.97 \\
\hline $\begin{array}{l}\text { Other government } \\
\text { facilities }\end{array}$ & -5.4 & -2.1 & 1.0 & 8.0 & 0.94 & 0.98 & 1.01 & 1.09 \\
\hline Private & 0.0 & 0.0 & 6.4 & 10.1 & 1.00 & 1.00 & 1.07 & 1.11 \\
\hline Other private & -9.0 & -47.6 & -2.6 & -37.5 & 0.91 & 0.51 & 0.97 & 0.57 \\
\hline Total & -6.4 & -10.1 & 0.0 & 0.0 & 0.93 & 0.90 & 1.00 & 1.00 \\
\hline
\end{tabular}

* Reference group is the most advantaged group "private providers", ** Reference group is the national average, *** O refers to outpatient services, I refers to inpatient services. Source: calculated using EHHSUES data in El Zanaty (2002). 


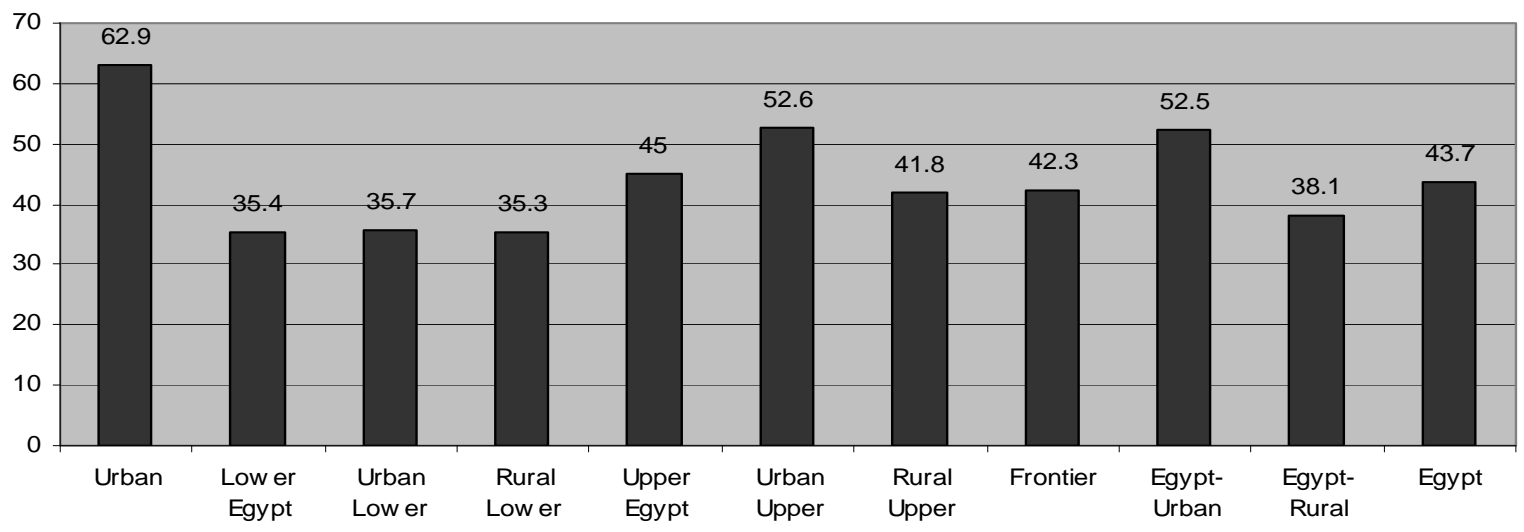

Figure 1. Iron Supplementation: Urban and Rural Areas 2008

Source: Constructed using DHS data in El Zanaty and Way (2009).

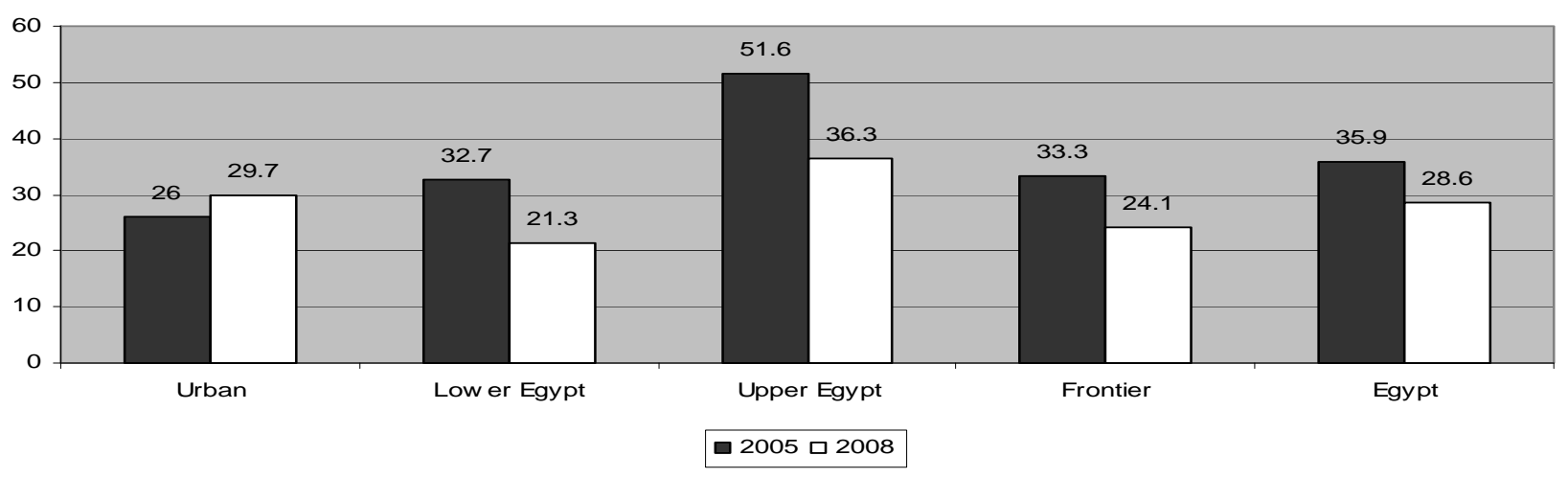

Figure 2. Infant Mortality Rates 2005, 2008

Source: Constructed using DHS data in El Zanaty and Way $(2006,2009)$

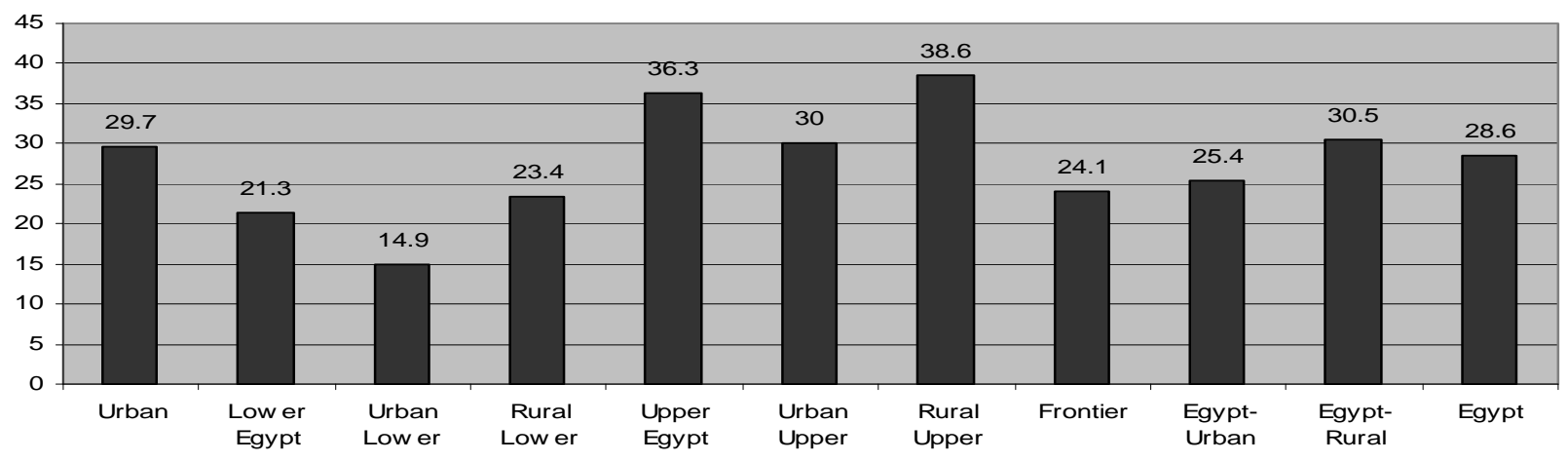

Figure 3. Infant Mortality: Urban and Rural Areas 2008

Source: Constructed using DHS data in El Zanaty and Way (2009). 


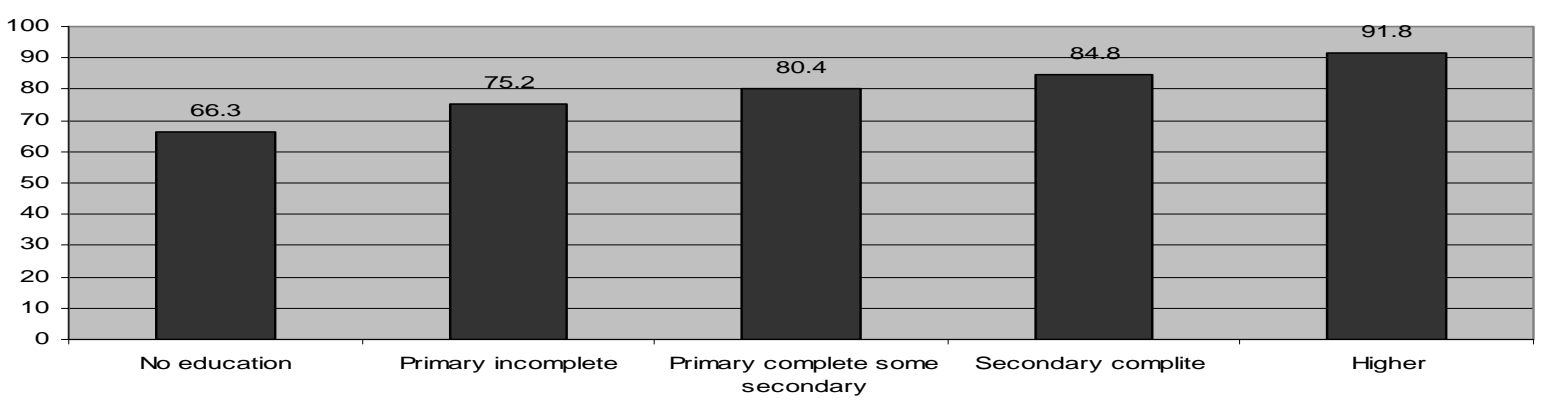

Figure 4a. Health Insurance Coverage by Education Level of the Head of Household

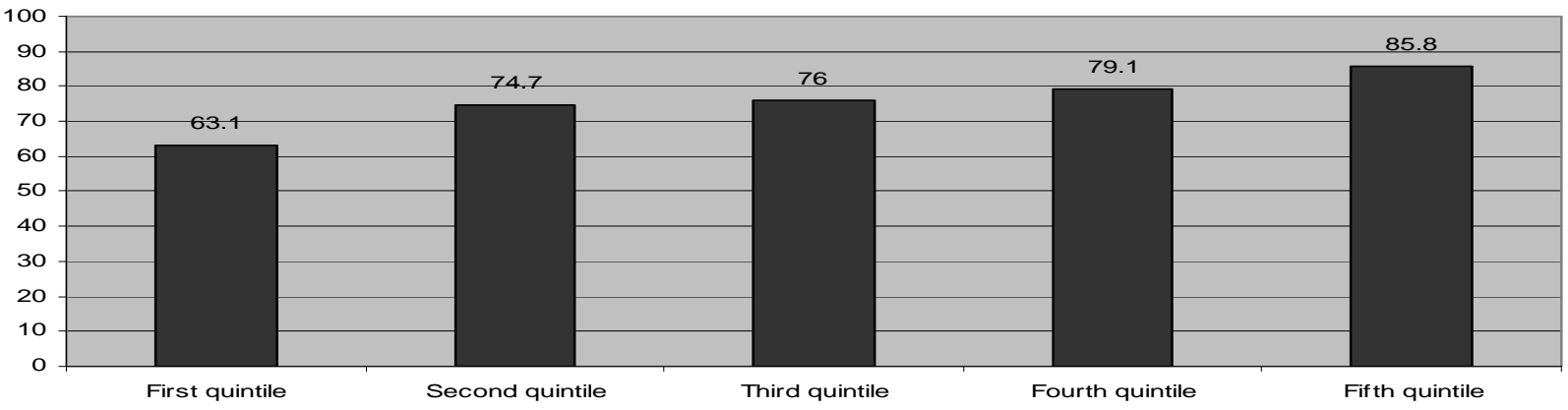

Figure 4b. Health Insurance Coverage by Wealth Quintile

Source: Constructed using EHHSUES data in El Zanaty (2002).

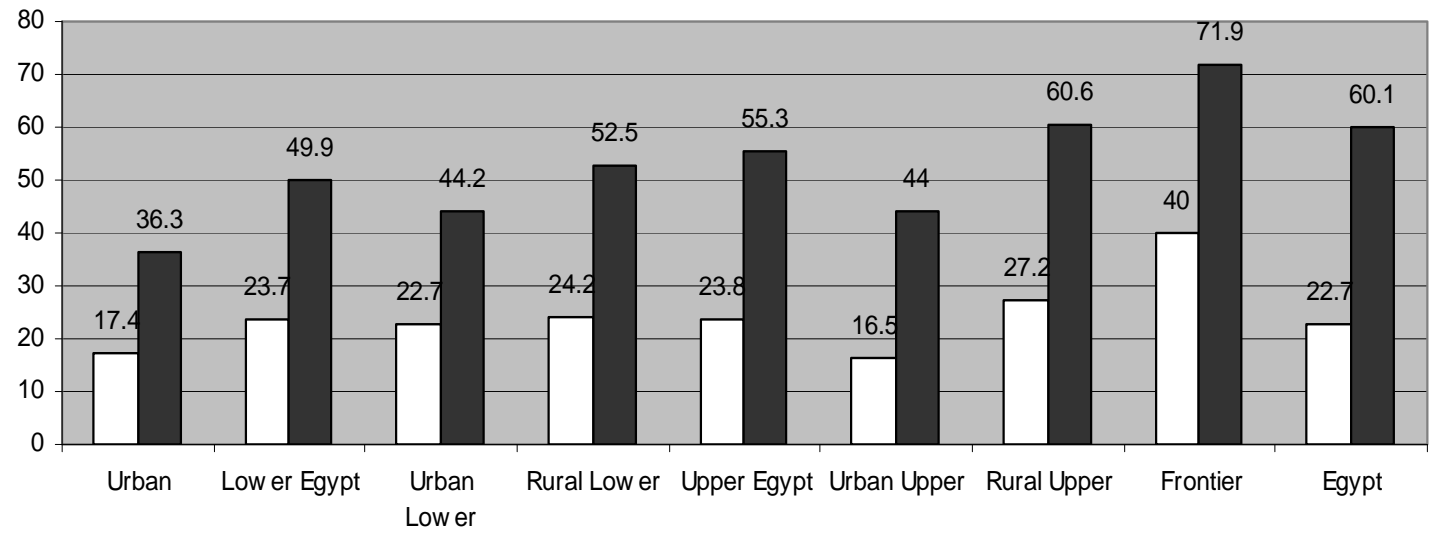

$\square$ Outpatient visits to MOHP/Total Outpatient visits\% $\square$ Inpatient visits to MOHP/Total Inpatient visits\%

Figure 5a. Using MOHP Services by Region 


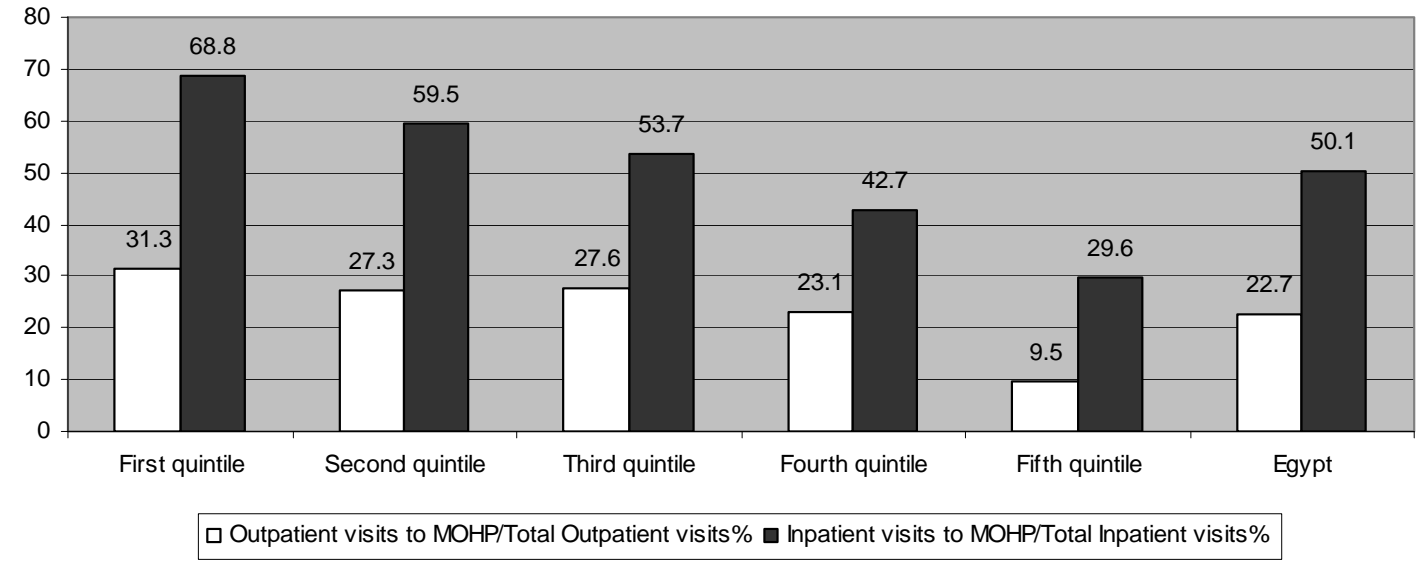

Figure 5b. Using MOHP Services by Wealth Quintile

Source: Constructed using EHHSUES data in El Zanaty (2002). 